Scientific Periodicals : The Philosophical Transactions and the Edinburgh Medical Journal

\title{
Hiltunen, Turo
}

John Benjamins

2019

Hiltunen , T 2019 , Scientific Periodicals : The Philosophical Transactions and the Edinburgh Medical Journal . in I Taavitsainen \& T Hiltunen (eds), Late Modern English Medical Texts :

Writing Medicine in the Eighteenth Century . John Benjamins , Amsterdam , pp. 317-326 . https://doi.org/10.1075/z.2

http://hdl.handle.net/10138/313952

https://doi.org/10.1075/z.221.11.7.hil

other

submittedVersion

Downloaded from Helda, University of Helsinki institutional repository.

This is an electronic reprint of the original article.

This reprint may differ from the original in pagination and typographic detail.

Please cite the original version. 


\title{
11.7 Periodicals: representativeness and text selection The Philosophical Transactions and Edinburgh Medical Journal
}

\author{
Turo Hiltunen
}

\section{Introduction}

The eighteenth century, which has been described as "the golden age of the scientific society" (Gross, et al. 2002: 70), saw a great proliferation of scientific and medical journals. The category Periodicals of the LMEMT corpus enables the study of linguistic and rhetorical developments specifically in the context of medicine in this increasingly important medium across the span of one hundred years.

The category Periodicals is different from the other categories in the LMEMT, in that it is defined by its publication format, not the topic of the texts. In other words, all texts in this category have been published in scientific journals, while the topics span several areas of medical research. This is consistent with how periodicals were treated in the EMEMT; the articles from The Philosophical Transactions formed a category of their own. We use the terms "journal" and "periodical" interchangeably throughout this volume to refer to texts in this category, although as Kronick (1991) observes, it is difficult to make distinctions between periodicals and newspapers, especially in the early history of the genre. ${ }^{1}$

Overall, the importance of the scientific article grew considerably over the course of the eighteenth century. Although the status of the book as the main vehicle for disseminating scientific knowledge remained unrivalled throughout the eighteenth century (Bazerman 1988: 80), the century witnessed an increase in the number of active journals in Europe from 7 to 118 (Kronick 1976). The growing

\footnotetext{
${ }^{1}$ Kronick (1991: 16-18) lists seven characteristics of the genre at the end of the eighteenth century, which derive from Kirchner's (1928-1931) work on German periodicals: periodicity, duration, collectivity, availability, continuity, timeliness, and universality.
} 
importance of the medium is also reflected in the composition of the LMEMT corpus, where this category accounts for over 20 per cent of the total number of words included. The category contains a substantial sample extracted from two prominent journals: The Philosophical Transactions of the Royal Society (henceforth Phil. Trans.), the landmark publication in the history of English empiricist science, and the Edinburgh Medical Journal (henceforth EMJ), a newly-established journal devoted solely to the study of medicine. ${ }^{2}$

\section{Sampling}

The two samples described here are primarily designed as components of the LMEMT, contributing to the aim of compiling a representative corpus of medical writing in the eighteenth century. In other words, they can be contrasted with each other, and with the other categories in the corpus (cf. Sinclair 2005). While they can reasonably be used for other purposes, we do not claim that they would be independently representative of the breadth and range of periodicals in the eighteenth century.

\section{1 The Philosophical Transactions}

Established in 1665, the Philosophical Transactions ${ }^{3}$ remains an important vehicle for communication in the eighteenth century. Medical topics feature prominently in the contents of the journal especially in the first decades after its establishment, which reflects the fact that the membership of the Royal Society at the time included a large number of medical practitioners (Hall 1971, Porter 1989). With the growth of specialized medical societies in the eighteenth century, the importance of medicine declined in purely scientific journals (McClellan 1985: 37-38), but medical topics continue to be discussed in the Phil. Trans. throughout the century.

\footnotetext{
${ }^{2}$ The Phil. Trans. and the EMJ have been widely studied in corpus linguistics, and articles published in these two journals are also available in previously released corpora, such as ARCHER (Biber et al. 1993: 6).

${ }^{3}$ The subject classification for Phil. Trans. in Kronick (1991) is Science-Societies-England.
} 
To obtain a representative sample of specifically medical texts in the Phil. Trans., it is first necessary to define a sampling frame, that is a list of eligible texts from which a random selection can be made (see Biber et al. 1993: 5). The sampling frame was created by compiling a list of all medical articles published in the journal between 1700 and 1800, with the help of the titles listed in the table of contents of each volume. Each article provisionally included in our selection was checked to confirm that it actually deals with questions of medicine. For the first four decades, our selection relies on the abridgement Medical essays and observations relating to the practice of physic and surgery (1745) edited by Samuel Mihles. ${ }^{4}$ When the list was ready, we divided it into ten clusters, corresponding to decades, and from each cluster randomly selected every third article.

The sample published as part of the corpus contains XXX articles and XXX words. It is comparable in size to the data set analysed by Bazerman $(1988: 63)^{5}$ but is more focused in terms of disciplinary coverage.

\subsection{Edinburgh Medical Journal}

In contrast with the well-established, general scientific journal Phil. Trans. described above, the Edinburgh Medical Journal represents a new stage in the history of medical periodicals: transactions of strictly medical societies established in the eighteenth century (Lefanu 1938). As part of the Scottish Enlightenment, Edinburgh became a major centre of medical theory and medical teaching, and the Edinburgh Medical Faculty was created in 1726 (Emerson 2004). Shapin (1974) characterizes medical science in the mid-eighteenth century as the "cornerstone of the Edinburgh scientific enterprise and its crowning glory" (1974: 98).

\footnotetext{
${ }^{4}$ Entry 990 in Kronick (1991).

${ }^{5} 100$ articles representing the genre of experimental report in life sciences.
} 
The first issue of the journal came out in 1733 under the title Medical Essays and Observations. We use the title Edinburgh Medical Journal to refer to this journal and other titles, listed in Table 1, following Atkinson (1992) and Kronick (1991).

\begin{tabular}{|c|c|c|}
\hline & Title & Years \\
\hline 1 & $\begin{array}{l}\text { Medical Essays } \\
\text { and Observations }\end{array}$ & $1733-1752$ \\
\hline 2 & $\begin{array}{l}\text { Essays and Observations, } \\
\text { Physical and Literary }\end{array}$ & $1754-1771$ \\
\hline 3 & $\begin{array}{l}\text { Medical and Philosophical } \\
\text { Commentaries }\end{array}$ & $1773-1795$ \\
\hline 4 & Annals of Medicine & $1796-1805$ \\
\hline 5 & $\begin{array}{l}\text { Edinburgh Medical } \\
\text { and Surgical Journal }\end{array}$ & $1805-1953$ \\
\hline 6 & Scottish Medical Journal & 1954 \\
\hline
\end{tabular}

Table 1. Titles subsumed under the Edinburgh Medical Journal. Our sample is based on titles 1-4.

As above, the first step in text selection was to define an appropriate sampling frame for the $E M J$. To this end, we produced a comprehensive list of the articles published in the journal 1733-1800, with the help of the table of contents of each volume of the journal, which we consulted through Eighteenth Century Collections Online (ECCO). This list required some pruning: we first excluded entries that were not actually proper articles. ${ }^{6}$ In addition, as shown in Figure 1, the vast majority of articles are a few pages long, but the sampling frame also includes some very long texts, which would dominate the category in terms of word count if they were included in the sample in their entirety. For this reason, we excluded articles longer than 15 pages. ${ }^{7}$ The pruned list of articles, summarized in Table 2 ,

\footnotetext{
${ }^{6}$ These included section headings like Front Matter, Title Page, Table of Contents, INTRODUCTION, Main Body, SECT. I. An Account of Books, as well as simple lists of books without any other prose text (these were occasionally published in Medical and Philosophical Commentaries under the title List of new books).

${ }^{7}$ These make up 19\% (216/1154) of the titles.
} 
was then clustered by decade, and random selection was employed within each cluster to acquire every tenth article. The resulting sample contains 94 articles, which make up 524 pages in the original layout, and ca. 160,000 words. As such, the sample constitutes a considerably larger collection of eighteenth century texts from this journal than the corpora used in previous studies. ${ }^{8}$

\begin{tabular}{|c|c|c|c|}
\hline Title & Volume & No. of articles & No. of pages \\
\hline Medical Essays & 1 & $42(39)$ & 307 \\
\hline \multirow{6}{*}{ and Observations } & 2 & $36(31)$ & 355 \\
\hline & 3 & $33(25)$ & 347 \\
\hline & 4 & $37(31)$ & 412 \\
\hline & 5 & $42(32)$ & 390 \\
\hline & 6 & $38(33)$ & 481 \\
\hline & Subtotal & 228(191) & 2,292 \\
\hline Essays and Observations, & 1 & $22(14)$ & 474 \\
\hline \multirow[t]{3}{*}{ Physical and Literary } & 2 & $36(29)$ & 443 \\
\hline & 3 & $47(39)$ & 586 \\
\hline & Subtotal & $105(81)$ & 1,503 \\
\hline Medical and Philosophical & 1 & $56(54)$ & 398 \\
\hline \multirow[t]{20}{*}{ Commentaries } & 2 & $63(60)$ & 398 \\
\hline & 3 & $57(52)$ & 419 \\
\hline & 4 & $51(46)$ & 423 \\
\hline & 5 & $51(45)$ & 418 \\
\hline & 6 & $56(51)$ & 432 \\
\hline & 7 & $44(38)$ & 429 \\
\hline & 8 & $32(27)$ & 413 \\
\hline & 9 & $44(36)$ & 481 \\
\hline & 10 & $31(22)$ & 399 \\
\hline & 11 & $32(22)$ & 438 \\
\hline & 12 & $29(20)$ & 459 \\
\hline & 13 & $28(20)$ & 459 \\
\hline & 14 & $34(24)$ & 493 \\
\hline & 15 & $33(22)$ & 501 \\
\hline & 16 & $31(21)$ & 425 \\
\hline & 17 & $23(13)$ & 556 \\
\hline & 18 & $38(29)$ & 475 \\
\hline & 19 & $27(18)$ & 411 \\
\hline & 20 & $27(20)$ & 382 \\
\hline & Subtotal & $787(641)$ & 8,809 \\
\hline \multirow[t]{2}{*}{ Annals of Medicine } & 1 & $34(25)$ & 428 \\
\hline & rand total & $1,154(938)$ & 13,032 \\
\hline
\end{tabular}

\footnotetext{
${ }^{8}$ Atkinson's (1992) diachronic study, for instance, included 70 texts in total, of which 20 were from the eighteenth century, selected from two volumes of the journal.
} 
Table 2. Sampling frame. Numbers in brackets indicate the number of articles which are shorter than 15 pages. The page counts are based on the tables of contents. 


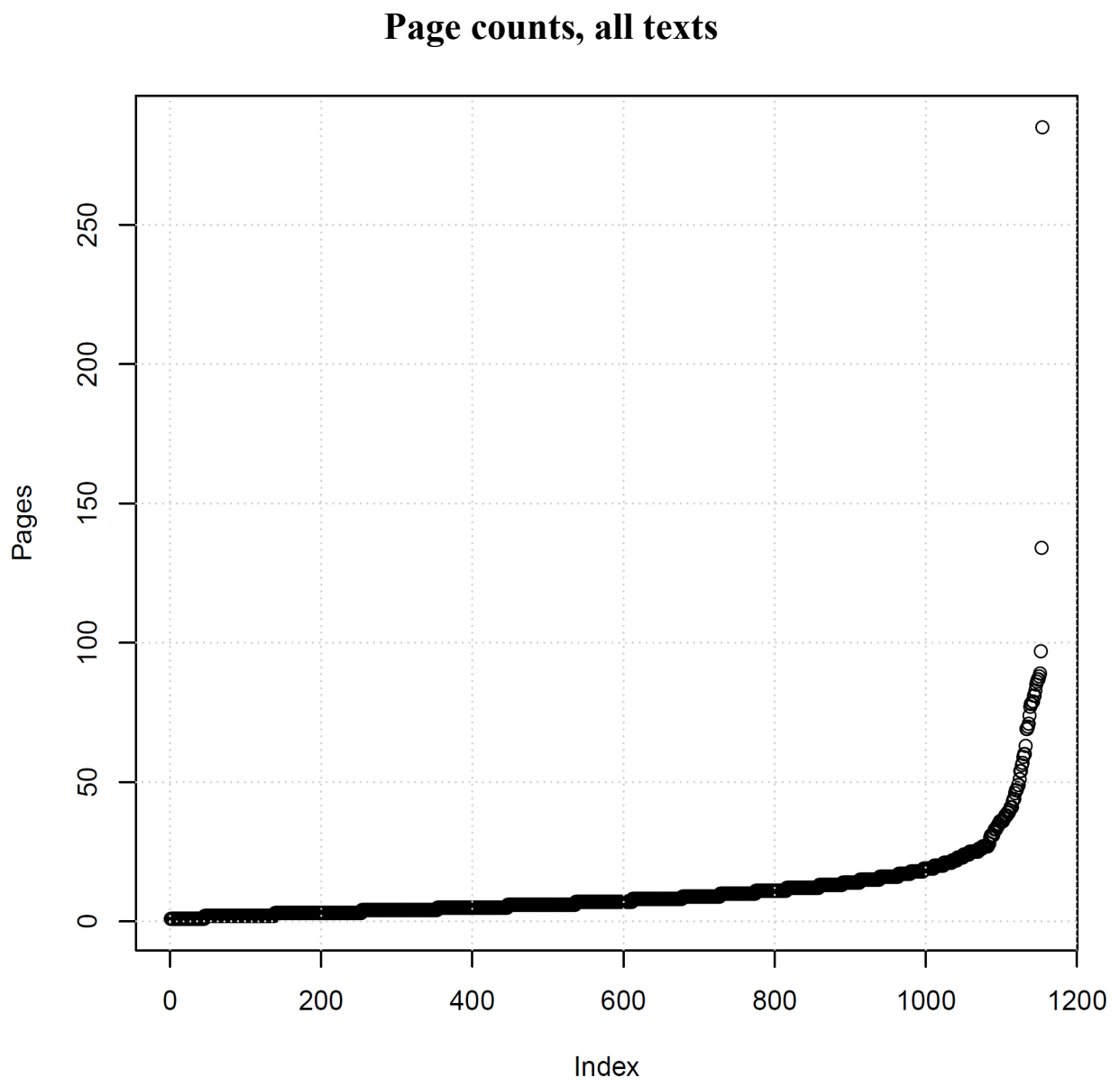

Figure 1. Page counts of all articles in the Edinburgh Medical Journal (1733-1800).

\section{Target audience}

The early volumes of the Phil. Trans. published contributions from a mixed group of authors, including a significant proportion of amateurs; this characteristic of English empiricism persisted well into the eighteenth century, and is reflected in the varied nature of composition, as well as in the predominance of the epistolary format (Gross et al. 2002: 91). At the same time, the increasing disciplinary specialization meant that articles were increasingly written by professionals and addressed to other professionals, especially towards the end of the century. In this sense, the readership of the EMJ is more specialized than that of the Phil. Trans., where medicine is just one area of interest among many. On the other hand, Shapin (1974: 101) observes that the landed and traditional professional classes also participated in the city's literate and scientific culture. 


\section{Discourse forms}

In some ways, the discourse of the Phil. Trans. in the eighteenth century represents a continuation of the styles established in the previous century. The epistolary and narrative forms, as shown by the following extracts (examples 1 and 2) from 1738. This discourse style is particularly characteristic of English periodicals in this century (Gross et al. 2002: 71).
Extracts of Two Letters from the Revd Dean Copping, F. R. S. to the President, concerning the Caesarian Operation performed by an ignorant Butcher; and concerning the extraordinary Skeleton mentioned in the foregoing Article.

SIR,

Dublin, March 16. 1737-8.

I Have transcribed a Case, which I received from a young Clergyman, who some time studied Physic, and knows the Woman: I shall probably see her at Clogher, where she now lives. The Case happened within these Two Years, but I cannot learn the exact Date at present.

As can be seen, example (1) is a letter addressed to the editor of the journal. The extract includes several instances of first-person pronouns (bold type), which reflects the author's personal tone and subjective point of view. The article continues in a narrative fashion (2):

(2) Sarah Mc Kinna, who now lives at Brentram, Two Miles from the City of Clogher, in the County of Tyrone, was married at the Age of Sixteen Years.

--Before her Marriage she never had the Appearance peculiar to Women; but, in a Month after her Marriage, those Appearances shewed themselves properly.

Another characteristic feature of the Phil. Trans. in this century is the interest in various curiosities of nature, although some shifts towards the norms of contemporary scientific discourse can already be detected. For instance, the following extract (3) giving an account of a "monstrous appearance" a frequently discussed topic in 17th century articles (Porter 1989: 285) - opens with a discussion of the status and value of such accounts. It displays an openly critical stance through lexical and 
mind) and also refers to the work of previous authors, albeit in an approximate way.

(3) It is much to be regretted, that the histories of monstrous appearances in the structure of the human body which are to be found in the works of the older writers, and even of many of the moderns, are so little to be depended upon. Few authors have contented themselves with giving a simple detail of facts that were extraordinary; but, from an over anxiety to make them still more wonderful, or from having given an implicit belief to the accounts received from the credulous and ignorant, they have commonly added circumstances too extravagant to deserve the attention of a reasonable mind, which prevent the reader from giving credit to any part of the narration. This has been so general, that whenever the history of any thing uncommon appears, the mind is impressed with a doubt of its authenticity, and requires some stronger evidence of the facts than the single testimony of an individual in other respects unimpeached in his veracity. (1790)

The style of this passage foreshadows the eventual displacement of the author-centred narrative discourse with a more objective and impersonal style focusing on the object of study and the methods of analysing it.

Despite the differences in scope, the $E M J$ obviously shares many similarities with the general science journal Phil. Trans.: as Atkinson (1992) observes, the EMJ is characterized by an empiricist ethos and an emphasis on the collection of observations, which are reported on using a "rhetoric of personal experience" (1992: 359-60). This discourse mode is illustrated in a passage from 1775 quoted as example (4), which opens a medical case report. It provides detailed information about time (italics), locations (underlined), and the identity of participants (bold type), and employs a narrative form with a strong authorial persona, as manifested in the frequent use of first person pronouns:

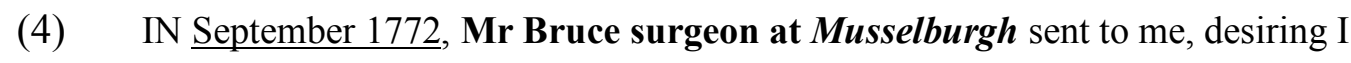
would meet him at Lord Abercorn's coal-work, one of the colliers having dislocated his left thigh-bone. I there found Messrs Bruce and Stewart surgeons in Musselburgh, and Messrs Simpson and Clarkson surgeons in Dalkeith, who were just begun to attempt the reduction by pullies. With these several trials were made; but the lacque round the knee slipping, it was taken off. By this means I had an opportunity of examining it. I found the left-knee protruding three or four inches further than the right, and the one 
could not be brought within eight or ten inches of the other, the foot being turned out. (Medical and Philosophical Commentaries, 1775)

According to Atkinson (1992), eighteenth-century case reports are typically focused on individual patients, showing little attempt at broader generalizations or theoretical synthesis. This is also true for the reports in our sample, which typically conclude with a statement of the outcome or resolution of the case, and occasionally a request for further debate on the issue, as in example (5):

(5) And I know an old lady (grandmother to the faid child), who fays fhe was born with the fmall-pox. It is certain, the is now up-wards of fixty (in good health), and never had any other.

Thefe facts I humbly mention to you. They involve a number of queries, which I hope in time will be both put and anfwered by fome of your numerous and very ingenious correfpondents. I only wilhed to give them fimply, and without any commentary.

A similar discourse style is present in experimental essays, which are also found in the $E M J$ sample, although the genre is more closely associated with the early Phil. Trans. (Atkinson 1999; cf. Hiltunen 2010). Example (6) quotes a brief extract from an essay on the medicinal waters of Moffat by Andrew Plummer, a Scottish physician (see also Taavitsainen, this volume):
Above fixty Years ago Mr. Mackaile publifhed a Topographico-fpagyrical Defcription of Moffat Wells; in which he concludes, but from very precarious Principles, that this Water is impregnated with the putid Sulphur of Antimony and Nitre; but in another Place he thinks it neceffary to add to thefe natural Sal Ammoniac: This Gentleman indeed writes in the Dialect of an Adept, but moft unlike a true Chemift, declares againft Experiments, and afferts, that an Analyfis of the Water would be to no Purpofe, and therefore never made the Trial. I fhall not trouble the Reader with any further Remarks on this Author, but fhall impartially relate the Experiments I made on this Water, and the Stones taken from the Vein on which it runs. (Plummer, Experiments on the Medicinal Waters of Moffat, EMJ, 1747)

As can be seen, Moffat criticizes a previous essay on these medicinal waters as unempirical, and offers a detailed 2,500-word account of his own experiments, including those which were unsuccessful (example (6)):

I made a great many Attempts to fix this Sulphur, and render it confpicuous, but without Succefs, and therefore I fhall not trouble the Reader with thefe fruitlefs Experiments. (Plummer, Experiments on the medicinal waters of Moffat, EMJ, 1747)

Also included in our sample are extensive reviews of continental medical books, which is a distinct genre in eighteenth-century periodicals, and one which has been shown to differ rhetorically from experimental reports and letters (Gray et al. 2011). The purpose of these reviews was typically to give the readership access to the ideas expressed in them, as shown in example (7), quoting the first paragraph of a review of a Latin treatise by Ignatio Radniczky (1756). Radniczky had done influential experiments of the dura mater in Prague, confirming their sensibility, contrary to the suggestions by the Swiss anatomist Albrecht von Haller (see Steinke 2005). 
(7) SEveral years ago a doctrine was introduced to the world, by the late celebrated Haller and his difciples, tending to prove, that the tendons, periofteum, dura mater, and fome other membranous parts, are all deftitute of fenfation. Various anfwers have been publifhed to this opinion; but as the Work now before us enters more fully upon this inveftigation than any we have met with, and as the Author's ideas are all fupported by a feries of well conducted experiments, we thall therefore give a particular detail of fuch, of thefe as appear to be moft conclufive. (Review of Specimen Inaugurale Medicum, EMJ, 1781)

\section{Continuity versus new trends}

Although periodization into centuries is a hypostatization, as "[n]othing of significance ends at the end of a century; nothing of significance begins at its beginning" (Gross et al 2002: 90), the eighteenth century can safely be treated as a period of consolidation and proliferation of medical publishing in periodicals. The two titles in focus, the Phil. Trans. and the EMJ, represent an increasingly important forum for combining experimental scientific research, in particular the careful recording of observations, with actual medical practice. In general terms, the discourse of both periodicals is still redolent of the seventeenth century Phil. Trans.: articles often focus on the particularities of individual cases (patients, illnesses, medicines) and haphazard details in the absence of a systematized research agenda (cf. Hiltunen 2010). Variation between individual texts is also considerable. This category enables the detailed study of the language and discourse of this increasingly important medium, anticipating major textual and rhetorical changes taking place from the 19th century onwards. 